\title{
Engines of creationism? Intelligent design, machine metaphors and visual rhetoric
}

\author{
Gunnar E. Höst and Gustav Bohlin
}

\section{Linköping University Post Print}

\section{Tweet}

N.B.: When citing this work, cite the original article.

Original Publication:

Gunnar E. Höst and Gustav Bohlin, Engines of creationism? Intelligent design, machine metaphors and visual rhetoric, 2015, Leonardo: Journal of the International Society for the Arts, Sciences and Technology, (48), 1, 80-81.

http://dx.doi.org/10.1162/LEON_a_00905

Copyright: Massachusetts Institute of Technology Press (MIT Press): Arts \& Humanities Titles etc

http://mitpress.mit.edu/main/home/default.asp?sid=19E29805-C0A0-4642-8ECD$\underline{\text { BACF5ADFF807 }}$

Postprint available at: Linköping University Electronic Press

http://urn.kb.se/resolve?urn=urn:nbn:se:liu:diva-113512 


\section{ENGINES OF CREATIONISM? - INTELLIGENT DESIGN, MACHINE METAPHORS AND VISUAL RHETORIC}

Gunnar E. Höst, Department of Science and Technology, Linköping University, Sweden E-mail: <gunnar.host@liu.se>.

Gustav Bohlin, Department of Science and Technology, Linköping University, Sweden E-mail: <gustav.bohlin@liu.se>.

Submitted: <leave for Editor to date $>$

\begin{abstract}
Machine metaphors are ubiquitous in the molecular sciences. In addition to their use by scientists, educators and popularizers of science, they have been promoted intensively by the Intelligent Design (ID) movement in arguments for the necessity of a god-like designer to account for the complexities of life at the molecular level. We have investigated the visual rhetoric employed in a movie by ID proponents, with particular emphasis on machine metaphors. After presenting examples, we argue that science communicators could reduce the persuasive impact of ID visual rhetoric based on machine metaphors by emphasizing that selfassembly is fundamental to molecular complexes.
\end{abstract}

\section{Introduction}

In his visionary work "Engines of Creation", Eric Drexler ponders the potentials of an industrial machine world of extreme miniaturization [1]. The use of such machine metaphors to describe aspects of molecular structure and function are commonplace in the scientific literature. For example, noting the highly coordinated moving parts in certain molecular complexes, Bruce Alberts suggested that analysis methods from engineering may help understand their function [2]. Machine metaphors have also been heavily used by proponents of Intelligent Design (ID) in their arguments against evolutionary theory. They argue that components of cells show evidence of design and therefore require a designer (following a tradition that began with William S. Paley). We have investigated a movie produced by ID proponents to understand how machine metaphors are used rhetorically to support ID arguments [3].

\section{Metaphors and visual representations of molecules}

Molecules are too small to be observed without powerful imaging technologies, and visual representations are therefore crucial for communicating the molecular world. Artists and designers of such visual representations must select and transform the available scientific data, but since we lack direct experiences of the sub-microscopic world, it is difficult to distinguish between scientific content and pure design choices. This problem is further compounded by the capacity of modern computer graphic technologies to render images and animations of cells and molecules that give the impression of photorealism.

Visual representations of molecular entities can be seen as analogical mappings, where the unfamiliar domain of a scientific concept is organized in relation to the familiar domain of visual objects. According to structure mapping theory, such comparisons typically map the objects and the relations between objects from one domain to another, but not necessarily the attributes of the objects [4]. For example, a red 'ball' typically indicates an oxygen atom in a depiction of a water molecule, while two white 'balls' indicate hydrogen atoms. Such an image is intended to convey the spatial relations between atoms of different types in the scientific concept of $\mathrm{H}_{2} \mathrm{O}$. The actual choice of colors for the balls in the visual model, however, is based solely on convention.

Similar analogical reasoning applies to machine metaphors in science. The Oxford English Dictionary definition of machine is "an apparatus using mechanical power and having several parts, each with a definite function and together performing a particular task". Such a definition allows protein assemblies to be compared with machines at the human scale, as suggested by Alberts. However, the fact that ordinary machines have been designed is irrelevant to Alberts' use of machine metaphors. The molecular machines described in Drexler's nanotechnology also fit the definition above, but unlike Alberts' they are explicitly designed. Science education research has shown that machine metaphors are sometimes interpreted too literally [5]. Some authors even argue against using machine metaphors at all, not least because of their use by ID proponents [6].

\section{Machine metaphors in the visual rhetoric of Intelligent Design}

We present examples of the use of machine metaphors in ID visual rhetoric in the movie "Unlocking the Mystery of Life". Our examples concern bacterial flagella, large protein complexes that allow some bacteria to 'swim'. ID proponent Michael Behe claims that the flagellum exhibits "irreducible complexity", which means that if one part is removed the flagellum would cease functioning. Behe argues that irreducible complexity cannot arise through evolution since the individual parts are considered useless unless they are introduced as a whole [7].

According to Jens Kjeldsen, the rhetorical device called evidentia, used by orators to persuade through a vivid and detailed presentation, is an important factor in visual rhetoric. In the first two examples, we point out some of the rhetorical qualities that support evidentia in images according to Kjeldsen [8]. The first example, where the bacterial flagellum is introduced, invokes a sense of presence by letting the viewer share a crucial experience with professor Behe. While showing a schematic image of a flagellum in a textbook [9], Behe describes his response:

Behe: I remember that the first time I looked into a biochemistry textbook and I saw a drawing of something called a bacterial flagellum, with all of its parts, with all of its glory, it had a propeller, a hook region and a drive shaft and $a$ motor and so on. I looked at that and said that "that is an outboard motor, that's designed", you know, that's no chance assemblage of parts. (15:5516:22)

The sense of presence is tightly coupled with realism and indexical documentation, which is strengthened in the movie by linking to conventional scientific representations. In the second example, an electron micrograph, very similar to Fig 1A, is positioned at the end of a computer-rendered cell:

Narrator: ...the molecular motors that drive bacteria through liquid, each depend upon a system of intricately arranged mechanical parts. These parts come into focus, when portions of a cell are magnified 50000 times. Biochemists have used electron micrographs like this one, to identify the parts and threedimensional structure of the flagellar motor. In the process, they have revealed a marvel of engineering on a miniaturized scale. (16:25-17:00)

Subsequently, a graphically rendered model of the flagellum with a distinctly machine-like appearance is built up to match the structure of the flagellum depicted by the micrograph [10]. The act of superposing the computer-rendered animation on a scientific image, which has an indexical relation to the depicted structure, may foster the audience's trust in the accuracy of the animation and authority of the movie. 
In the third example, the movie supports a claim that not only the flagellar structure, but also its assembly, is irreducibly complex, by extending the machine metaphor to also include machine assembly. Here, the metaphor 'formation of a flagellum is like building a house' is introduced. Visually, a blueprint and an animation that show the different stages of erecting a house is followed by an animation depicting a stepwise build-up of a flagellum. Just like building a house, the different parts of the flagellum need to be assembled in a tightly regulated and precise sequence, which requires a complex system of machines to coordinate the assembly instructions, according to the movie's narration. ID proponent Paul Nelson expands on this:

Nelson: ...you see in order to construct that flagellar mechanism, or tens of thousands of other such mechanisms in the cell, you require other machines to regulate the assembly of these structures, and those machines themselves require machines for their assembly. (27:50 28:05)

It is not shown how the pieces of the house come together or how the components of the flagellum are assembled. Thus, viewers must 'fill in' the missing workers who build the house (cf. Fig 1B). Similarly, a viewer may assume that analogical implicit 'molecular workers' actually build the flagellum, especially given the movie's claim that special machines are needed for assembly. After all, if the message is that machines require a designer, it may seem reasonable to also expect builders.

\section{Breaking point of the machine metaphor: Who builds the machine?}

The visual rhetoric of the movie supports a literal interpretation of the machine metaphor, in which parts of cells are equated with machines. Discrepancies in the ID message may then be expected to arise where molecular machines differ from machines that we know from daily life. In addition to an exaggerated machine-likeness [11], we suggest that the process of machine assembly may be another such discrepancy.

The formation of a flagellum is undoubtedly complex. However, the overall impression conveyed by the movie is that it requires a level of detailed control that is similar to that required for humans to assemble macroscopic technological artifacts. This
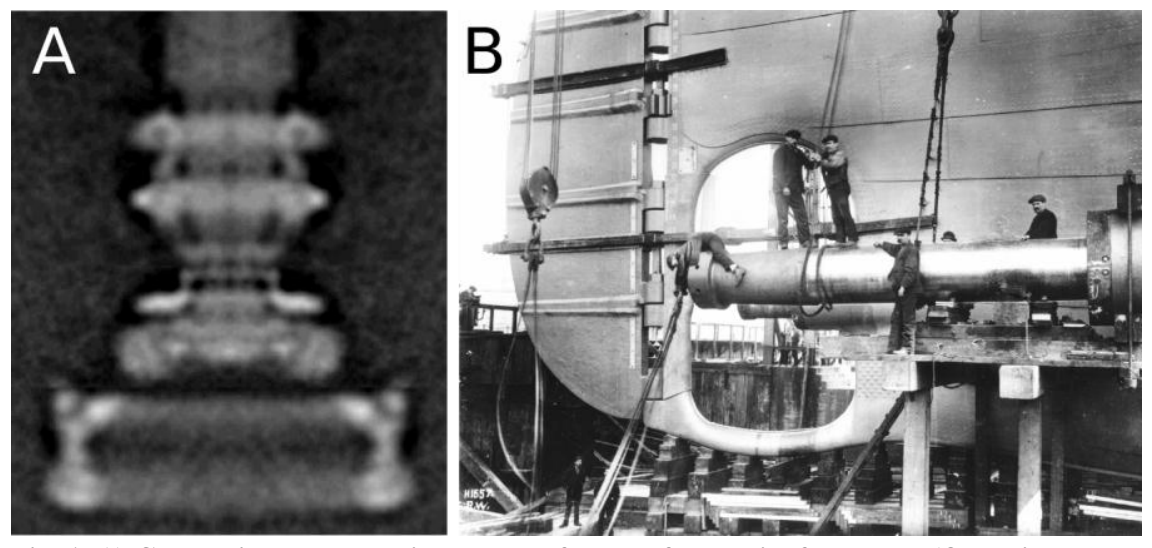

Fig. 1. A) Composite electron micrograph of parts of bacterial flagellum. (ㄷ David DeRosier.) B) RMS Titanic's propeller shaft installation. (Photo @ Anonymous, 1911.)

is more like the molecular assembly lines envisioned by Eric Drexler, in which machines called 'assemblers' perform the detailed manual assembly of nanoscale objects, than the processes of self-assembly that underlie formation of biological molecular complexes. Another peculiarity is the claim that flagellar assembly requires special machines which, in turn, require more machines. It is not specified which components of the cell this refers to, but it could be construed to imply an infinite regress. Together with the implicit 'molecular workers' analogy described above, this may lead viewers to interpret the message to be that the actual assembly of the flagellum, rather than evolution of the assembly pathway, is impossible without intelligent intervention.

With regard to ID, Niall Shanks has pointed out that self-organization and self-assembly are examples of natural causal mechanisms that can account for complexity and organization in complex systems [12]. The capacity for selfassembly, that is, a spontaneous formation of ordered structures resulting from random interactions between the components [13], indicates the extraordinary differences between molecular machines and the machines we know from everyday experience. Doren Recker has suggested that the machine metaphor is persuasive because it seems to make intuitive sense, as long as we do not 'look again' [14]. Given that machine metaphors are emphasized in the rhetoric used in ID, we suggest that the flaws in the ID argument may be exposed by highlighting the breakdown of the machine metaphor in the random nature of molecular self-assembly.

\section{Acknowledgements}

Grants 2011-5569 and 2012-5344 from the Swedish Research Council (Vetenskapsrådet) supported this work.

\section{References and Notes}

1. K. Eric Drexler, Engines of Creation: The Coming Era of Nanotechnology (New York: Anchor Press, 1986).

2. Bruce Alberts, "The Cell as a Collection of Protein Machines: Preparing the Next Generation of Molecular Biologists," Cell 92, (February 1998), 291-294.

3. Stephen C. Meyer and W. Peter Allen, Unlocking the Mystery of Life (2002), Illustra Media, film.

4. Dedre Gentner, "Structure-Mapping: A

Theoretical Framework for Analogy," Cognitive Science 7, (1983), pp. 155-170.

5. Mari Stadig Degerman, Caroline Larsson and Jan Anward, "When metaphors come to life - at the interface of external representations, molecular phenomena, and student learning," International Journal of Environmental \& Science Education 7 , No. 4 (October 2012) pp. 563-580.

6. Massimo Pigliucci and Maarten Boudry, "Why Machine-Information Metaphors are Bad for Science and Science Education," Science \& Education 20, No. 5-6 (May 2011), pp. 453-471.

7. Michael J. Behe, Darwin's Black Box: The Biochemical Challenge to Evolution. (New York: Simon and Schuster, 2006).

8. Jens E. Kjeldsen, "Billeders retorik (The rhetoric of images)," in Hanne Roer and Marie Lund Klujeff, eds., Retorikkens aktualitet (København: Hans Reitzels, 2009).

9. The textbook page shown is fabricated, with a schematic image of a flagellum superposed onto page 69 of [7]

10. Paul J. Wendel, "Mechanical Metaphors in Unlocking The Mystery of Life ," Paper presented at the Ninth International History, Philosophy, and Science Teaching Conference, University of Calgary, Alberta, Canada, (June 2007).

11. Mark Perakh, "Flagella Myths. How Intelligent Design Proponents Created the Myth that Bacteria look like Man-made Machines," Skeptic 14, No. 3 (2008).

12. Niall Shanks, God, the Devil, and Darwin: A critique of Intelligent Design Theory (New York, USA: Oxford University Press, 2004).

13. George M. Whitesides and Bartosz Grzybowski, "Self-assembly at all Scales," Science 295, No. 5564 (March 2002), pp. 2418-2421.

14. Doren Recker, "How to Confuse Organisms with Mousetraps: Machine Metaphors and Intelligent Design," Zygon 45, No. 3 (September 2010) pp. 647-664. 